\title{
Is neighborhood racial/ethnic composition associated with depressive symptoms? The multi-ethnic study of atherosclerosis
}

\author{
Christina Mair ${ }^{\mathrm{a}, \mathrm{g}, *}$, Ana V. Diez Roux ${ }^{\mathrm{a}, \mathrm{b}}$, Theresa L. Osypuk ${ }^{\mathrm{c}}$, Stephen R. Rapp ${ }^{\mathrm{d}}$, \\ Teresa Seeman ${ }^{\mathrm{e}}$, Karol E. Watson ${ }^{\mathrm{f}}$ \\ ${ }^{a}$ Department of Epidemiology, University of Michigan, Room 3655, 109 S Observatory, Ann Arbor, MI 48109-2029, United States \\ ${ }^{\mathrm{b}}$ Center for Integrative Approaches to Health Disparities, Department of Epidemiology, University of Michigan, MI, United States \\ ${ }^{\mathrm{c}}$ Northeastern University, Bouve College of Health Sciences, Department of Health Sciences, MA, United States \\ ${ }^{\mathrm{d}}$ Department of Psychiatry and Behavioral Medicine E Division of Public Health Sciences Wake Forest University School of Medicine, MA, United States \\ e Departments of Medicine E Epidemiology, David Geffen School of Medicine at UCLA, CA, United States \\ ${ }^{\mathrm{f}}$ Division of Cardiology, David Geffen School of Medicine at UCLA, CA, United States \\ ${ }^{\mathrm{g}}$ Prevention Research Center, 1995 University Ave., Suite 450, Berkeley, CA 94704, USA
}

\section{A R T I C L E I N F O}

Article history:

Available online 12 May 2010

\section{Keywords:}

Neighborhoods

Depressive symptoms

Mental health

Race/ethnicity

Ethnic density effect

USA

\begin{abstract}
A B S T R A C T
The racial/ethnic composition of a neighborhood may be related to residents' depressive symptoms through differential levels of neighborhood social support and/or stressors. We used the Multi-Ethnic Study of Atherosclerosis to investigate cross-sectional associations of neighborhood racial/ethnic composition with the Center for Epidemiologic Studies-Depression (CES-D) scale in adults aged 45-84. The key exposure was a census-derived measure of the percentage of residents of the same racial/ethnic background in each participant's census tract. Two-level multilevel models were used to estimate associations of neighborhood racial/ethnic composition with CES-D scores after controlling for age, income, marital status, education and nativity. We found that living in a neighborhood with a higher percentage of residents of the same race/ethnicity was associated with increased CES-D scores in African American men ( $p<0.05$ ), and decreased CES-D scores in Hispanic men and women and Chinese women, although these differences were not statistically significant. Models were further adjusted for neighborhood-level covariates (social cohesion, safety, problems, aesthetic quality and socioeconomic factors) derived from survey responses and census data. Adjusting for other neighborhood characteristics strengthened protective associations amongst Hispanics, but did not change the significant associations in African American men. These results demonstrate heterogeneity in the associations of race/ethnic composition with mental health and the need for further exploration of which aspects of neighborhood environments may contribute to these associations.
\end{abstract}

(c) 2010 Elsevier Ltd. All rights reserved.

\section{Introduction}

It has long been argued that the racial/ethnic composition of a neighborhood may be related to the presence of depressive symptoms in residents (Halpern, 1993). There are two main hypotheses regarding the relation between neighborhood racial/ ethnic composition and depressive symptoms. Each of these hypotheses postulates a different relation between race/ethnic composition and depression. The first hypothesis (referred to as the ethnic density hypothesis) (Halpern \& Nazroo, 2000) proposes that persons who live in neighborhoods with a greater proportion of residents of their own race or ethnicity have better mental health

\footnotetext{
* Corresponding author. Tel.: +1 5108835762 .

E-mail address: cmair@prev.org (C. Mair).
}

outcomes (and lower levels of depressive symptoms) than persons who live in neighborhoods with fewer people of their race/ ethnicity. The second hypothesis (which we will refer to as the residential segregation hypothesis) postulates that persons who live in neighborhoods with a greater proportion of residents of their own race or ethnicity have worse mental health outcomes (and higher levels of depressive symptoms) than persons who live in neighborhoods with fewer people of their race/ethnicity.

According to the ethnic density hypothesis (Halpern, 1993) greater ethnic density is beneficial to mental health because ethnic density is associated with social environments characterized by greater levels of social support and social cohesion and with better access to resources through social connections (Henderson et al., 2005). For example, immigrants living in neighborhoods with large proportions of immigrants may have stronger social ties, more social support from kinship networks or community institutions, or 
better access to resources distributed through dense networks than immigrants living in neighborhoods where they are the minority (Eschbach, Ostir, Patel, Markides, \& Goodwin, 2004; Fernandez Kelly \& Schauffler, 1996; Velez-Ibanez, 1993). In contrast, immigrants living away from immigrant-dense areas may experience isolation (Fernandez Kelly \& Schauffler, 1996).

On the other hand, according to the residential segregation hypothesis, greater neighborhood concentrations of certain race/ ethnic groups are associated with adverse mental health outcomes because of the consequences of residential segregation. For example, factors such as institutional racism, forced segregation due to historical and contemporary discrimination in housing markets, and truncated economic opportunities among racial/ ethnic minority groups may result in concentrations of race/ethnic or immigrant groups in certain geographic areas. These areas are often disadvantaged in terms of physical and social characteristics (Acevedo-Garcia \& Osypuk, 2008; Massey, 2001) which in turn places residents in segregated neighborhoods at higher risk of depression (Iceland \& Scopilliti, 2008; Williams \& Collins, 2001). In other words, higher concentration of certain race/ethnic groups is associated with worse mental health because, in the context of residential segregation, race/ethnic composition serves as a proxy for adverse social and physical contexts, including higher prevalence of stressors, fewer social assets to buffer stressors, and poorer access to resources. For example, in the US, predominantly African American neighborhoods are often (though not always) associated with greater poverty and higher crime rates (Massey, 1995: pp. 1203-1232; Morenoff, 2003; Williams \& Collins, 2001) and regions with high racial residential segregation exhibit large differences in the neighborhood environments associated with racial/ethnic composition (Acevedo-Garcia, Osypuk, McArdle, \& Williams, 2008; Osypuk, Galea, McArdle, \& Acevedo-Garcia, 2009). Although countries differ in the degree of residential segregation by race/ ethnicity, these mechanisms have been hypothesized to operate in may industrialized countries receiving substantial numbers of immigrants (Becares, Nazroo, \& Stafford, 2009; Halpern \& Nazroo, 2000; Pickett \& Wilkinson, 2008; Veling et al., 2008; Whitley, Prince, McKenzie, \& Stewart, 2006).

The relative importance of the processes outlined above may differ for different racial/ethnic groups. For example, among relatively recent immigrants (e.g. Hispanics in the US), the protective effects of higher percents of neighborhood immigrants may predominate (ethnic density hypothesis) whereas in other groups (e.g. African Americans in the US) the adverse effects of residential segregation resulting from a long history of structural racism (residential segregation hypothesis) may predominate. For these reasons, the direction of the association of race/ethnic composition with depressive symptoms may vary by ethnic group within a country.

Few studies have investigated the association between neighborhood racial/ethnic composition and depressive symptoms in multiple ethnic groups living in the same country. Individuals in the UK were found to have lower levels of neurotic mental health symptoms (depression, anxiety, fatigue, sleep problems) in areas with higher own-group ethnic concentration, but the strength of the associations was stronger for minority groups than whites (Halpern \& Nazroo, 2000). In the US, studies focusing on both African Americans and whites have generally found no evidence that neighborhood racial composition is associated with depressive symptoms after adjustment for confounders (Henderson et al., 2005; Kubzansky et al., 2005). No US studies of which we are aware have comprehensively investigated associations of race/ethnic composition with depressive symptoms in multi-ethnic samples.

We used data from the Multi-Ethnic Study of Atherosclerosis (MESA) to investigate the ethnic density and residential segregation hypotheses through the examination of cross-sectional associations of neighborhood racial/ethnic composition with depressive symptoms amongst healthy adults aged 45-84 years from four different racial/ethnic groups. We also examined if any of the observed associations were explained by specific neighborhood attributes, including neighborhood poverty, levels of social cohesion, and stressors. Given the high magnitude and form of racial residential segregation in the US, (Massey, 2001) we hypothesized that high concentrations of African American residents would be associated with higher levels of depressive symptoms among African Americans, while high concentrations of white residents would be associated with lower levels of depressive symptoms among white residents. The positive mental health association for whites may operate either via the residential segregation theory or the ethnic density theory, since both posit better neighborhood environments for whites living in neighborhoods with high concentrations of other whites. In contrast, we hypothesized that Hispanics and Asians would exhibit positive mental health associations of living in neighborhoods with high proportions of coethnics due to the ethnic density theory, which is more likely to operate among relatively recent immigrants. Although we examined these patterns in the US, where residential segregation is particularly stark, the investigation of associations in the US may yield insights into the mechanisms operating in many different contexts, and is likely to be relevant to other industrialized countries receiving large numbers of immigrants.

\section{Methods}

\section{Study setting and population}

The Multi-Ethnic Study of Atherosclerosis (MESA) is a ten-year longitudinal study of men and women aged 45 to 84. Participants were enrolled at six study field centers (Baltimore MD, New York NY, Chicago IL, Los Angeles CA, Minneapolis MN, and Forsyth County NC) between August 12000 and July 30 2002. At each site, a probability sample of participants (range: 1066-1319) was selected through a variety of population-based approaches, including lists of area residents (all sites), Health Care Financing Administration (HCFA) lists of area residents (for participants $\geq 65$ of age in all sites), area residents enrolled in a union health plan (in New York City), and random digit dialing (New York City and Los Angeles) (Diez Roux et al., 2005). All sites aimed to enroll an equal number of men and women and at least two different racial/ethnic groups. Participants were free of clinically evident cardiovascular disease at the time of enrollment (Bild et al., 2002). The data used in this study came from the baseline examination data collected during 2000-2002. Surveys were administered in English, Spanish, Cantonese, or Mandarin. Institutional review boards at all participating study centers approved the study, and informed consent was obtained from all study participants.

\section{Data collection and variables}

The primary outcome for this study was participants' depressive symptoms, measured in MESA participants using the 20-item Center for Epidemiologic Studies Depression (CES-D) Scale (Radloff, 1977). Each scale item is scored from 0 to 3, with a higher score representing more depressive symptoms. The potential range of this scale is $0-60$, with a score of 16 often used as the cutoff for clinical depression. The CES-D scale was used as a continuous variable, since it was not highly skewed.

The main exposure variable was a census-derived measure of the percentage of people of the same race/ethnicity in a study participant's census tract. We used data from the 2000 US census to 
derive the percentages of each of four race/ethnic groups in each census tract: percent non-Hispanic African American, Hispanic, non-Hispanic white, and non-Hispanic Asian. Each of these variables was transformed into units of $10 \%$ increase in order to ease interpretation of results, as a $1 \%$ change in racial/ethnic composition is not large enough to be relevant and a change of $100 \%$ is beyond the range of variation observed in the data.

Additional neighborhood characteristics were assessed through a questionnaire administered to MESA participants. Four neighborhood dimensions linked to depressive symptoms in other study populations (Aneshensel \& Sucoff, 1996; Fitzpatrick, Piko, Wright, \& LaGory, 2005; Hadley-Ives, Stiffman, Elze, Johnson, \& Dore, 2000) as well as in the MESA population (Mair et al., 2009) were examined as possible confounders or mediators of the race/ethnic composition effect. These dimensions were as follows: one domain related to assets in the social environment, e.g. social cohesion (constructed from five items) and three domains related to the construct of neighborhood stressors (neighborhood safety (three items), neighborhood problems (seven items), and aesthetic quality (two items)) (Ball, Bauman, Leslie, \& Owen, 2001; Mujahid, Diez Roux, Morenoff, \& Raghunathan, 2007; Sampson, Raudenbush, \& Earls, 1997). All four scales had acceptable ecometric properties, i. e. they were reliable measures of area-level constructs and were related to other neighborhood-level properties in the expected direction (Mujahid et al., 2007; Osypuk, Roux, Hadley, \& Kandula, 2009), and were similar to scales used in prior work (Echeverria, Diez-Roux, Shea, Borrell, \& Jackson, 2008). For each MESA participant we created a measure for his or her neighborhood based on the mean responses of all other MESA participants residing within one mile of the participant. One-mile buffers were used instead of census tracts in order to better capture variation in these dimensions over space and in the individual-level exposure to these conditions in the sample. Each neighborhood measure was transformed into units of standard deviations (for the full sample), in order to allow comparisons across scales and measurements. Higher values of the scales indicate higher social cohesion, safety, more problems, and a better aesthetic quality.

We also investigated two neighborhood socioeconomic status variables that were created using factor analysis of nineteen variables from the 2000 US census (Mujahid, Diez Roux, Morenoff, Raghunathan, Cooper, et al., 2008). The first factor score consisted of six items representing housing and income/wealth (\% vacant housing, \% of homes with no telephone, \% of homes with no vehicle, $\%$ unemployed, median household income, and \% poverty) (SES Factor 1 ). This factor explained $61 \%$ of variance. The second factor score used three measures to represent education, occupation, and income/wealth (\% of persons 25 or older with bachelors degree or higher, \% with non-managerial occupation, \% households with interest, dividends, or net rental income) (SES Factor 2), and explained $22 \%$ of variance. Despite their conceptual overlap, both factors were included in this analysis as each one explained a substantial proportion of the variance across the nineteen items. For both SES Factors, higher scores indicate lower socioeconomic position.

Individual-level covariates associated with both depressive symptoms and neighborhood conditions were also used in the analysis. These variables included gender, age, race/ethnicity, annual income, highest level of education achieved, marital status, and nativity, all assessed at the MESA baseline exam. Age was categorized into four groups (45-54, 55-64, 65-74, 75-84). Race and ethnicity were classified as Caucasian, African American, Chinese, and Hispanic, based on self-report using questions from the Year 2000 US census. Total gross family income was categorized into five levels: $<\$ 20,000, \$ 20,000-34,999, \$ 35,000-49,999$, $\$ 50,000-74,999$, and $\$ 75,000+$. Education was categorized as: less than high school, completed high school, some college or a trade or Associate's degree, Bachelor's degree, and graduate/professional degree. Marital status was categorized as: married/living as married, widowed, divorced/separated, single, and prefer not to say. Four categories of nativity were used: foreign-born and in the US less than 10 years, foreign-born and in the US 10-19 years, foreign-born and in the US $20+$ years, and US-born. Additional adjustment for self-reported health did not substantially change results and was not included in final analyses.

\section{Data analysis}

Analyses were stratified by gender, in order to allow for potential gender differences in the association between depressive symptoms and neighborhood characteristics which have been found in several studies (Berke, Gottlieb, Moudon, \& Larson, 2007; Fitzpatrick et al., 2005; Gutman \& Sameroff, 2004). Analyses were also stratified by race/ethnicity, because the main exposure of interest (\% people of the same racial/ethnic background in participants' census tracts) differed for each racial/ethnic group and because our hypotheses involved effect modification by race/ ethnicity. We examined the distribution of all individual-level and neighborhood-level covariates, by gender and racial/ethnic group.

Associations between neighborhood context and mental health may be non-linear; for example it may be that the protective social factors only become apparent above a certain concentration. In order to determine whether the associations between CES-D score and \% racial/ethnic composition were linear, we used scatter plots and generalized additive models (GAMs) to look at the shape of the associations and test for non-linearity. We also examined associations between our primary neighborhood-level variables, \% residents of each racial/ethnic group, and the six other neighborhood-level covariates by modeling the neighborhood characteristics as a function of neighborhood race/ethnic composition. The correlations between the neighborhood variables were low to moderate (Pearson Correlation Coefficients were mostly in the $0.2-0.5$ range).

Two-level multilevel models with a random intercept for each census tract were used to estimate associations of ethnic composition (percent of people of the same racial/ethnic background) with depressive symptoms. The random intercept was used to account for any residual within-tract correlation in outcomes. All models were adjusted for age, income, and education, as these are potentially key confounders of the relationship between depressive symptoms and neighborhood racial/ethnic composition. Models for Hispanic and Chinese participants additionally adjusted for nativity; over $90 \%$ of white and black participants were native-born, so nativity was not adjusted for in these groups. We then examined whether any observed associations of ethnic composition with depressive symptoms were explained by other neighborhood factors (social cohesion, neighborhood problems, neighborhood safety, aesthetic quality, neighborhood socioeconomic status). We added these variables to our models, first one at a time, and then in combination. None of the individual- or neighborhood-level covariates simultaneously included in any models were highly correlated. We did not adjust for antidepressant use because it was not associated with neighborhood race/ethnic composition and because of the known methodological limitations of adjusting for a variable that is a consequence of the outcome (Hernan, Hernandez-Diaz, \& Robins, 2004). All models were also run after additional adjustment for MESA study sites as dummy variables.

The associations between neighborhood racial/ethnic composition and depressive symptoms may differ by individual-level characteristics such as education or income. Several studies have found cross-level interactions between individual race/ethnicity (Gary, Stark, \& LaVeist, 2007) and income (Weich, Lewis, \& Jenkins, 
2001; Weich, Twigg, Holt, Lewis, \& Jones, 2003) and neighborhood environments. We therefore examined cross-level interactions between individual-level education and income and neighborhood racial/ethnic composition. Since only one of the sixteen interactions was statistically significant, final models are presented without any interaction terms. All models were fitted using SAS Proc Mixed (Littell, Milliken, Stroup, \& Wolfinger, 1996).

In sensitivity analyses we used propensity score matching in order to examine the robustness of our results to alternate ways of adjusting for confounding and to restrict comparisons to persons with overlapping covariate distributions (Joffe \& Rosenbaum, 1999). Since our exposure was continuous, we created racial/ethnic- and gender-specific tertiles of neighborhood race/ethnic composition. Those subjects in the middle tertile were dropped from the analysis, since the goal was to compare subjects living in neighborhoods with substantially different racial/ethnic concentrations. We then used propensity scores to match persons in the top and bottom tertile on age, income, education, marital status, (and nativity, for Hispanic and Chinese participants only) using caliper matching of 0.2 standard deviations, which removes $98 \%$ of the bias in a normally distributed covariate under certain conditions (Rosenbaum \& Rubin, 1985) and still allowed for most of our participants to be matched. We were able to match 1288 pairs of subjects, with a range of 118 (Chinese) to 551 (white) pairs for each racial/ethnic group. Paired $t$-tests for CES-D scores were then performed for these matched pairs.

Of the 6814 MESA participants, 6191 participated in the MESA Neighborhood Study (on which these analyses are based) and 5812 had complete information on gender, age, race/ethnicity, income, education, address of residence and CES-D score. We also excluded Chinese and Hispanic participants missing nativity status $(n=141)$ and 4 participants who lived in sites with $<5$ people of the same racial/ethnic group enrolled in MESA. This left a total of 5667 study participants. Participants not included in the final sample resembled those included in terms of key covariates.

\section{Results}

Table 1 shows the distribution of study participants' individualand neighborhood-level characteristics. Hispanics were only enrolled in New York, Minneapolis, and Los Angeles, and Chinese participants only came from Chicago and Los Angeles. White participants were enrolled at all six sites, and African Americans participated in every location except Minneapolis. Chinese and Hispanic women reported the lowest incomes, and white men the highest (Table 1). 37\% of Hispanic males and $44 \%$ of Hispanic females reported less than a high school education, while $35 \%$ of white males and $23 \%$ of Chinese males had a graduate/professional degree. The majority of study participants were married, with African American women as a low outlier (only 35\% reported being married/living as married, as compared with $91 \%$ of Chinese men and $62 \%$ overall). Chinese and Hispanic populations were mainly foreign-born ( $>95 \%$ of Chinese and $>60 \%$ of Hispanics were born outside of the United States). Each racial/ethnic group had the highest mean neighborhood race/ethnic concentration for their own racial/ethnic group, with whites and African Americans living in neighborhoods with an average concentration of $61-66 \%$ of their own racial/ethnic group.

Table 2 shows the mean CES-D score for each of the gender and racial/ethnic groups by individual-level demographic characteristics. Within each racial/ethnic group, men had lower CES-D scores than women (Table 2). Hispanic and white men and women living in New York had higher CES-D scores than their counterparts in other study sites. Chinese participants in Chicago had significantly higher levels of depressive symptoms than those in Los Angeles.
Income was strongly inversely associated with depressive symptoms in all groups except Chinese participants and Hispanic men (Table 2). Lower levels of depressive symptoms were strongly associated with higher levels of education amongst African American men and women and white women. Married study participants had lower CES-D scores than separated, divorced, widowed, and never married individuals across all groups, with the exception of Chinese men. Hispanic women born in the U.S. had much lower CES-D score than those born outside the U.S. $(p<0.01)$, while the opposite held true for Chinese women: those born in the U.S. had higher levels of depressive symptoms than those not born in the US, although differences across place of birth/years in the US categories were not statistically significant $(p=0.16)$ (Table 2 ).

Fig. 1 shows the mean age-adjusted CES-D score for each of the eight gender and racial/ethnic groups, stratified by quartiles of the \% same racial/ethnic group in participants' census tracts. Among African American men, those living in tracts with a greater \% of African Americans had higher CES-D scores $(p=0.12)$ (Fig. 1). Hispanic women living in areas with more Hispanic residents tended to have higher CES-D scores, although a drop was observed in the highest quartile. Among Chinese women the middle categories had the lowest CES-D scores. No clear patterns were observed for the other race/ethnic and gender groups, and none of the associations were statistically significant at a $p<0.05$ level. The GAM plots (not shown) adjusted for education, age, income, and nativity (Hispanic and Chinese participants only) largely confirmed the patterns observed in Fig. 1. Given that non-linearities were often non-statistically significant, all associations were subsequently modeled as linear.

Table 3 shows the bivariate associations between \% racial/ethnic composition and the other neighborhood characteristics (safety, problems, aesthetic quality, social cohesion, neighborhood SES), for each racial/ethnic group. Higher levels of neighborhood problems and lower levels of social cohesion, aesthetic quality, and safety were associated with higher \% of African Americans (amongst African American participants), higher \% Hispanics (Hispanic participants), higher \% Asian (Chinese participants), and lower \% white (white participants). Lower neighborhood socioeconomic status was associated with higher \% African American and Hispanic and lower \% white (Table 3).

Table 4 shows mean differences in CES-D scores associated with a $10 \%$ increase in racial/ethnic concentration in African American, Hispanic, Chinese and white women and men, after adjustment for (1) individual-level age, income, education and nativity (Chinese and Hispanic participants only); (2) the same individual-level covariates plus other neighborhood-level covariates (added one at a time into models); and (3) the individual-level covariates plus all neighborhood-level covariates. A greater concentration of African Americans was not associated with depressive symptoms in African American women, although adjusting for neighborhood safety created a non-significant negative association (mean difference for a $10 \%$ increase $-0.14(95 \% \mathrm{CI}-0.32,0.05))$. Higher concentrations of the same racial/ethnic group in participants' census tracts were associated with increased CES-D levels for African American men (mean difference for a $10 \%$ increase 0.26 (95\% CI 0.12, 0.41)). This association remained largely unchanged after adjustment for other neighborhood-level variables. Among Hispanic women, higher neighborhood concentrations of the same racial/ethnic group were associated with lower CES-D levels after adjustment for individuallevel factors, with the association becoming significant after additional adjustment for the neighborhood SES Factor 1 score (mean difference for a $10 \%$ increase $-0.39(95 \% \mathrm{CI}-0.40,-0.02)$ ). Among Hispanic men, greater \% Hispanics in the tract was also associated with lower CES-D, although this association was only statistically significant after adjustment for SES Factor 1 and 2 (mean difference 
Table 1

Selected individual- and neighborhood-level characteristics of study participants, by gender and race/ethnicity.

\begin{tabular}{|c|c|c|c|c|c|c|c|c|c|c|}
\hline & & \multirow[t]{2}{*}{ All Participants } & \multicolumn{2}{|c|}{ African American } & \multicolumn{2}{|l|}{ Hispanic } & \multicolumn{2}{|l|}{ Chinese } & \multicolumn{2}{|l|}{ White } \\
\hline & & & Women & Men & Women & Men & Women & Men & Women & Men \\
\hline & & $(n=5667)$ & $(n=837)$ & $(n=669)$ & $(n=608)$ & $(n=571)$ & $(n=339)$ & $(n=321)$ & $(n=1192)$ & $(n=1130)$ \\
\hline \multirow{31}{*}{$\begin{array}{l}\text { Individual-Level } \\
\text { Characteristics }\end{array}$} & Study Site (\% distribution) & & & & & & & & & \\
\hline & Forsyth county, NC & 15.0 & 22.8 & 22.6 & & & & & 21.9 & 21.9 \\
\hline & New York, NY & 16.1 & 22.9 & 19.9 & 34.4 & 31.7 & & & 9.1 & 8.0 \\
\hline & Baltimore, MD & 15.8 & 30.0 & 28.9 & & & & & 18.4 & 20.4 \\
\hline & Minneapolis, MN & 15.9 & & & 28.6 & 31.0 & $\cdot$ & & 23.6 & 23.8 \\
\hline & Chicago, IL & 17.9 & 16.6 & 18.7 & & & 40.1 & 36.8 & 22.2 & 20.6 \\
\hline & $\begin{array}{l}\text { Los Angeles, CA } \\
\text { Age (years) (\% distribution) }\end{array}$ & 19.3 & 7.7 & 10.0 & 37.0 & 37.3 & 59.9 & 63.2 & 4.8 & 5.4 \\
\hline & $45-54$ & 29.2 & 30.9 & 30.6 & 30.4 & 30.1 & 27.1 & 26.8 & 29.6 & 26.7 \\
\hline & $55-64$ & 28.4 & 29.4 & 28.7 & 27.6 & 28.9 & 28.9 & 28.0 & 28.4 & 27.7 \\
\hline & $65-74$ & 29.5 & 29.3 & 29.6 & 27.8 & 26.8 & 31.0 & 30.2 & 29.0 & 31.5 \\
\hline & $\begin{array}{l}75-84 \\
\text { Annual income (dollars) (\% distribution) }\end{array}$ & 12.9 & 10.4 & 11.1 & 14.1 & 14.2 & 13.0 & 15.0 & 12.9 & 14.1 \\
\hline & $<20,000$ & 21.9 & 23.7 & 15.7 & 42.8 & 30.8 & 45.4 & 35.2 & 13.4 & 6.4 \\
\hline & $20,000-34,999$ & 20.6 & 25.6 & 18.2 & 29.9 & 28.2 & 21.8 & 19.9 & 18.5 & 11.5 \\
\hline & $35,000-49,999$ & 16.3 & 19.0 & 17.6 & 14.0 & 17.0 & 8.6 & 11.5 & 17.8 & 16.5 \\
\hline & $50,000-74,999$ & 17.4 & 18.8 & 23.2 & 8.7 & 12.6 & 10.3 & 12.8 & 19.0 & 21.6 \\
\hline & $\begin{array}{l}75,000+ \\
\text { Education (\% distribution) }\end{array}$ & 23.9 & 13.0 & 25.3 & 4.6 & 11.4 & 13.9 & 20.6 & 31.3 & 44.2 \\
\hline & $<$ High school & 15.6 & 9.4 & 10.6 & 44.2 & 37.0 & 29.5 & 15.0 & 5.4 & 3.6 \\
\hline & Completed high school & 18.3 & 19.4 & 17.9 & 23.9 & 19.8 & 21.5 & 12.8 & 20.6 & 12.2 \\
\hline & Some College/associate/trade & 28.8 & 36.1 & 34.8 & 23.9 & 29.8 & 21.2 & 20.3 & 31.4 & 24.0 \\
\hline & Bachelor's degree & 18.4 & 18.0 & 19.4 & 4.9 & 7.0 & 19.2 & 29.0 & 20.8 & 25.5 \\
\hline & $\begin{array}{l}\text { Graduate/Professional Degree } \\
\text { Marital Status (\% distribution) }\end{array}$ & 18.9 & 17.1 & 17.2 & 3.1 & 6.5 & 8.6 & 23.1 & 21.9 & 34.7 \\
\hline & Married/Living as Married & 61.7 & 35.1 & 61.0 & 49.7 & 70.4 & 72.9 & 90.7 & 57.6 & 76.5 \\
\hline & Widowed & 12.3 & 24.0 & 6.7 & 17.9 & 7.0 & 16.5 & 2.5 & 15.4 & 4.9 \\
\hline & Divorced/separated & 16.7 & 27.6 & 19.6 & 23.4 & 16.3 & 6.8 & 5.0 & 17.0 & 9.7 \\
\hline & Never married & 8.5 & 11.6 & 11.7 & 8.1 & 5.3 & 3.8 & 1.9 & 9.2 & 8.8 \\
\hline & Prefer not to say & 0.8 & 1.7 & 1.1 & 1.0 & 1.1 & & & 0.8 & 0.2 \\
\hline & Nativity (\% distribution) & & & & & & & & & \\
\hline & Foreign-born and in the U.S. $<10$ Years & 3.5 & $\mathrm{n} / \mathrm{a}^{\mathrm{a}}$ & $\mathrm{n} / \mathrm{a}$ & 7.1 & 4.9 & 18.6 & 16.5 & $\mathrm{n} / \mathrm{a}$ & $\mathrm{n} / \mathrm{a}$ \\
\hline & Foreign-born and in the U.S. $10-19$ Years & 6.2 & $\mathrm{n} / \mathrm{a}$ & $\mathrm{n} / \mathrm{a}$ & 9.4 & 8.2 & 33.6 & 30.8 & $\mathrm{n} / \mathrm{a}$ & $\mathrm{n} / \mathrm{a}$ \\
\hline & Foreign-born and in the U.S. $20+$ Years & 19.0 & $\mathrm{n} / \mathrm{a}$ & $\mathrm{n} / \mathrm{a}$ & 51.3 & 47.3 & 44.3 & 47.7 & $\mathrm{n} / \mathrm{a}$ & $\mathrm{n} / \mathrm{a}$ \\
\hline & U.S. Born & 70.3 & $\mathrm{n} / \mathrm{a}$ & $\mathrm{n} / \mathrm{a}$ & 32.2 & 39.6 & 3.5 & 5.0 & $\mathrm{n} / \mathrm{a}$ & $\mathrm{n} / \mathrm{a}$ \\
\hline \multirow{10}{*}{$\begin{array}{l}\text { Neighborhood-Level } \\
\text { Characteristics } \\
\text { (mean (s d)) }\end{array}$} & \% African American in census tract & $25.2(31.6)$ & $61.0(32.2)$ & $64.3(31.4)$ & $9.7(13.9)$ & $9.5(14.6)$ & $2.9(6.4)$ & $2.2(5.0)$ & $15.2(19.8)$ & $15.6(20.5)$ \\
\hline & \% Hispanic in census tract & $21.2(25.9)$ & $14.3(21.2)$ & $11.9(18.1)$ & $49.9(30.4)$ & $47.9(31.8)$ & $23.0(20.8)$ & $24.0(20.9)$ & $12.4(16.3)$ & $10.7(14.3)$ \\
\hline & \% White in census tract & $42.0(33.0)$ & $20.8(27.6)$ & $20.0(27.3)$ & $28.2(28.6)$ & $31.1(31.8)$ & $31.8(27.8)$ & $33.4(28.9)$ & $64.1(23.9)$ & $65.7(23.3)$ \\
\hline & $\%$ Asian in census tract & $9.3(16.0)$ & $2.0(4.2)$ & $1.9(4.9)$ & $9.4(13.3)$ & $9.0(13.4)$ & $40.1(24.3)$ & $38.3(23.0)$ & $5.9(7.8)$ & $5.5(7.2)$ \\
\hline & SES Factor 1 score (high = lower SES) & $0.21(1.03)$ & $0.69(1.00)$ & $0.57(1.02)$ & $0.81(1.01)$ & $0.67(1.13)$ & $0.00(0.94)$ & $-0.11(1.00)$ & $-0.24(0.74)$ & $-0.29(0.77)$ \\
\hline & SES Factor 2 score (high = lower SES) & $-0.39(1.27)$ & $0.08(0.98)$ & $0.04(0.94)$ & $0.31(1.03)$ & $0.27(1.06)$ & $-0.50(1.09)$ & $-0.56(1.12)$ & $-0.97(1.31)$ & $-1.02(1.28)$ \\
\hline & Social cohesion 1 mile $^{\mathrm{b}}$ & $3.52(0.21)$ & $3.52(0.21)$ & $3.55(0.22)$ & $3.44(0.21)$ & $3.45(0.22)$ & $3.46(0.15)$ & $3.46(0.15)$ & $3.57(0.19)$ & $3.59(0.21)$ \\
\hline & Neighborhood problems 1 mile $^{\mathrm{c}}$ & $1.51(0.22)$ & $1.59(0.21)$ & $1.57(0.21)$ & $1.58(0.22)$ & $1.57(0.23)$ & $1.32(0.17)$ & $1.30(0.17)$ & $1.48(0.18)$ & $1.48(0.19)$ \\
\hline & Neighborhood safety 1 mile $^{\mathrm{d}}$ & $3.61(0.40)$ & $3.45(0.37)$ & $3.47(0.38)$ & $3.45(0.33)$ & $3.44(0.34)$ & $3.72(0.31)$ & $3.75(0.34)$ & $3.76(0.39)$ & $3.77(0.40)$ \\
\hline & Aesthetic quality 1 mile $\mathrm{e}^{\mathrm{e}}$ & $3.39(0.31)$ & $3.30(0.31)$ & $3.34(0.31)$ & $3.29(0.33)$ & $3.30(0.35)$ & $3.61(0.22)$ & $3.65(0.22)$ & $3.42(0.27)$ & $3.43(0.28)$ \\
\hline
\end{tabular}

a $\mathrm{n} / \mathrm{a}=$ not applicable (racial/ethnic groups with $>90 \%$ US-born).

${ }^{\mathrm{b}}$ Social cohesion consists of 5 items (scale scored from 1 to 5, high = more cohesion): People willing to help their neighbors; People in neighborhood don't get along (reverse-coded); People in neighborhood can be trusted; People in neighborhood do NOT share the same values (reverse-coded); Close-knit neighborhood.

" Neighborhood problems consists of 7 items (scale scored from 1 to 4 , high = more problems): Poor sidewalks in neighborhood is a problem; Trash and litter in neighborhood is a problem; Lack of playgrounds/parks in

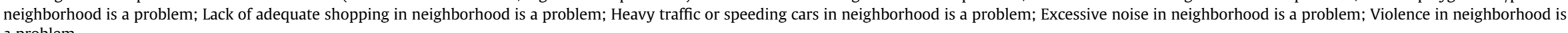
a problem.

d Safety consists of 3 items (scale scored from 1 to 5 , high = safer): I feel safe walking in my neighborhood, day or night; Violence is a problem in my neighborhood (reverse-coded); How safe is neighborhood from crime?.

e Aesthetic quality consists of 2 items (scale scored from 1 to 5 , high = good aesthetic): There is a lot of trash and litter on the street in my neighborhood; There is a lot of noise in my neighborhood. High = Good aesthetic. 
Table 2

Mean baseline CES-D score (Standard Deviation) by selected demographic characteristics $(n=5667)$.

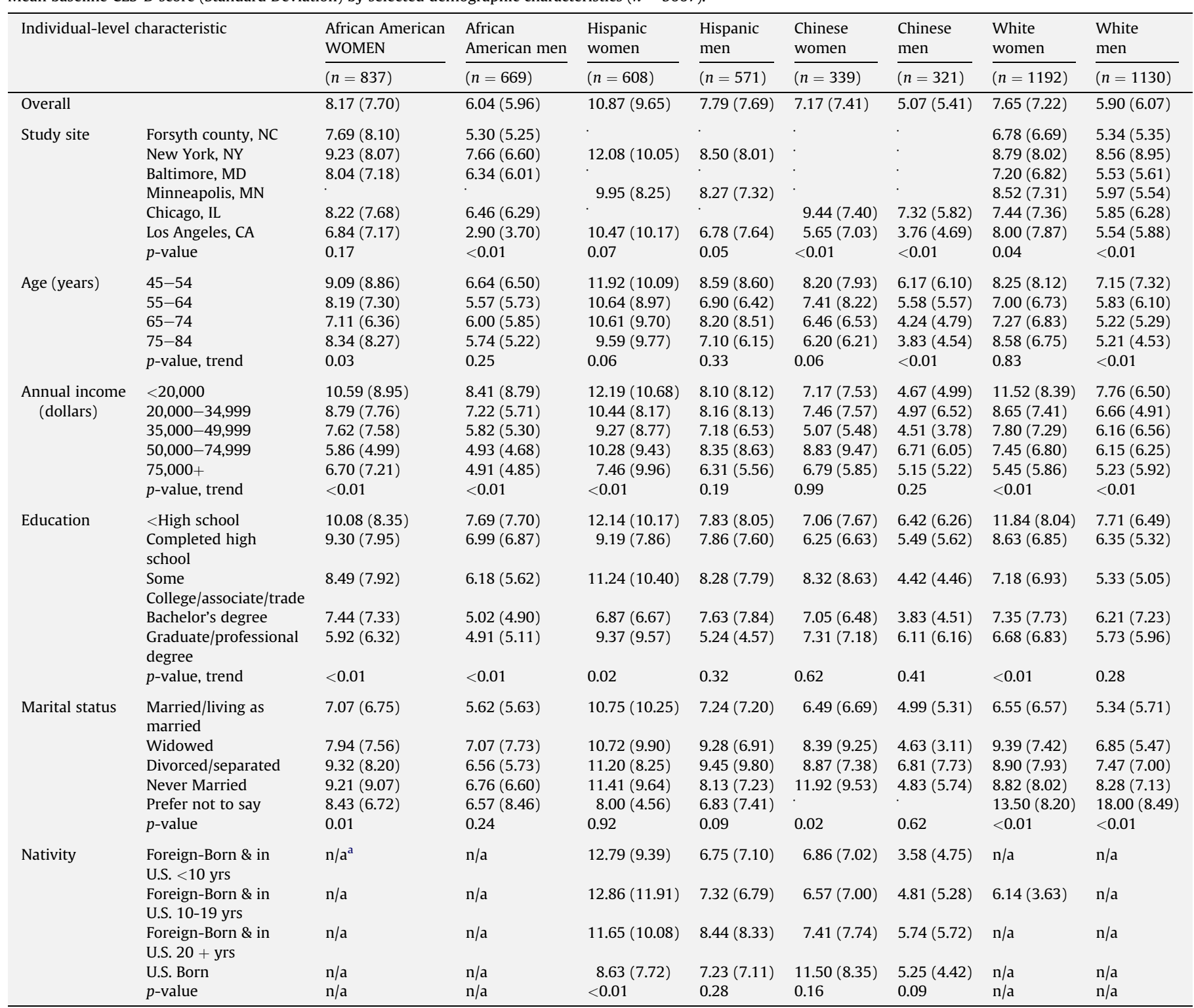

${ }^{\mathrm{a}} \mathrm{n} / \mathrm{a}=$ not applicable.

after adjusting for SES Factor 2 score $-0.33(-0.65,-0.01))$. Chinese women living in neighborhoods with higher concentrations of Asians had non-significantly lower CES-D scores (mean difference for a $10 \%$ increase in Asian concentration in models controlling for individual-level variables $-0.35(-0.76,0.06)$. This association was reduced in a model controlling for all neighborhood variables (mean difference $-0.14(-0.56,0.28)$ ). No associations were observed for Chinese men. A weak, non-significant negative association was observed in white men and women, with adjustment for SES Factor 2 increasing the strength of the association (mean difference for a $10 \%$ increase in white concentration $-0.21(95 \% \mathrm{CI}$ $-0.40,-0.02)$, women and $-0.16(-0.33,0.01)$, men).

Controlling for study site weakened the negative association observed in Hispanic men, eliminated the association in Chinese women, and created a positive, non-statistically significant association for Chinese men. There was no change in the strength of associations for Hispanic women, African American or white study participants. Global significance tests for interaction by study site were non-significant for all eight race/ethnicity and gender groups (results not shown).

The results of propensity score matched analyses were qualitatively similar to those observed in regression analyses. $44-83 \%$ of the participants in the bottom and top tertiles were matched across groups (number of matched pairs ranging from 118 to 551). The only statistically significant association between race/ethnic composition and depression was observed in African American men: those in the highest tertile of African American census tract concentration had a mean CES-D score 2.00 (95\% CI 0.77, 3.23) points higher than those in the lowest (after matching on propensity scores based on age, marital status, income, and education) (data not shown). Differences between tertiles were not statistically significant for any of the other groups, but the directions of the (non-significant) associations remained the same as in regression analyses. 


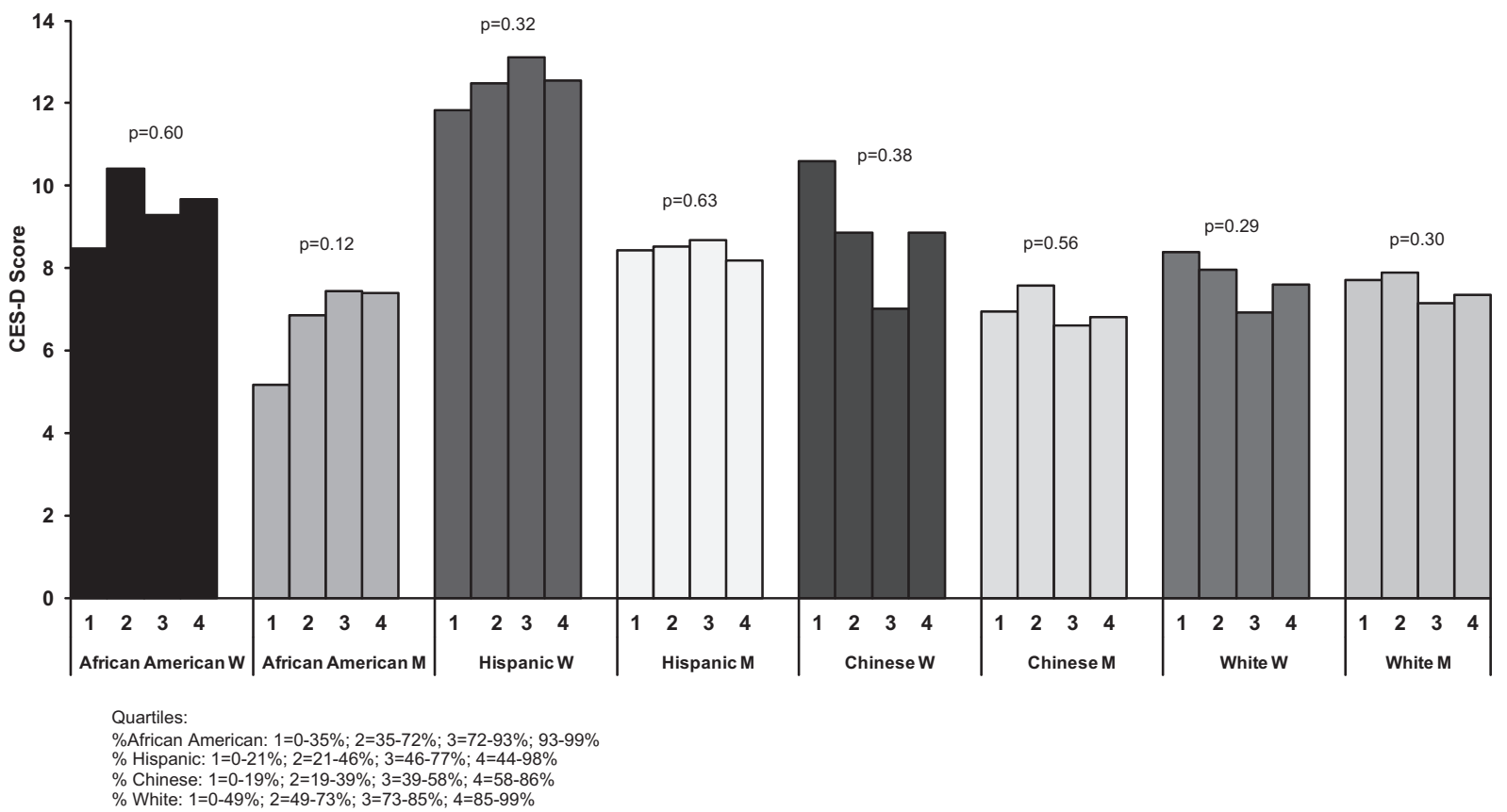

Fig. 1. Mean age-adjusted baseline CES-D score by quartiles of percent racial/ethnic group in census tract $(n=5667)$.

\section{Discussion}

Depression was associated with neighborhood racial/ethnic group concentration in African American men, Hispanic men and women and Chinese women after controlling for individual-level covariates. Living in a neighborhood with a higher concentration of African Americans was associated with higher mean CES-D scores in African American men. This association was not explained by other neighborhood characteristics, such as neighborhood aesthetic environment, safety, social cohesion, or the neighborhood socioeconomic environment. In contrast, higher neighborhood concentrations of the same racial/ethnic group were associated with lower CES-D levels for Hispanic women and men after adjustment for neighborhood socioeconomic characteristics, although this was somewhat reduced after controlling for other neighborhood characteristics. Greater concentrations of Asians were also associated with lower CES-D scores in Chinese women, although these associations were not statistically significant at the $p<0.05$ level.

Our prior research found that neighborhood characteristics are related to depressive symptoms (Mair et al., 2009). In this paper, we examined the contribution of these characteristics to differences in depression by racial/ethnic composition. The specific neighborhood-level measures investigated as explanatory variables (including neighborhood social cohesion, safety, problems, aesthetic environment, and SES conditions) did not fully explain the associations observed despite the fact that they were linked to depression in prior work in the same cohort and were all independently associated with the percent of each racial/ethnic composition group. While the absolute sizes of the associations with neighborhood racial/ethnic composition were relatively small, tending to be about three points on the 60 point scale from the lowest to the highest concentrations, they were comparable in magnitude to the differences found for key individual-level predictors of depression, such as income and education.

This study is one of the first to examine associations of neighborhood racial/ethnic composition and depressive symptoms amongst multiple racial/ethnic and gender groups. The diverse study sample allowed us to compare associations across groups. Our study adds to the literature on the mental health effects of racial/ethnic segregation by documenting that the direction of the association between racial/ethnic segregation and depression differs by gender and race/ethnicity. The large number of other neighborhood characteristics available in MESA allowed us to examine whether any associations were due, in part or wholly, to other neighborhood conditions associated with neighborhood racial/ethnic composition. In general adjustment for other neighborhood factors did not explain the patterns observed. However, among Hispanics residence in higher \% Hispanic neighborhoods

Table 3

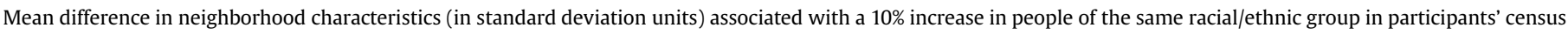
tracts, by race/ethnicity $(n=5667)$

\begin{tabular}{|c|c|c|c|c|}
\hline Neighborhood Variable & $\%$ African American & \% Hispanic & $\%$ Asian & \% White \\
\hline SES Factor 1 score & $0.65(0.50,0.81)^{*}$ & $2.13(2.01,2.25)^{*}$ & $1.22(1.05,1.38)^{*}$ & $-1.99(-2.09,-1.89)^{*}$ \\
\hline SES Factor 2 score & $1.65(1.45,1.84)^{*}$ & $2.70(2.55,2.85)^{*}$ & $-0.09(-0.13,-0.05)^{*}$ & $-1.07(-1.15,-0.98)^{*}$ \\
\hline Social cohesion & $-0.13(-0.29,0.03)$ & $-0.38(-0.55,-0.21)^{*}$ & $-0.76(-1.01,-0.52)^{*}$ & $0.36(0.26,0.46)^{*}$ \\
\hline Neighborhood problems & $0.95(0.80,1.11)^{*}$ & $0.67(0.50,0.83)^{*}$ & $0.25(0.02,0.49)^{*}$ & $-1.04(-1.15,-0.94)^{*}$ \\
\hline Neighborhood safety & $-1.46(-1.62,-1.30)^{*}$ & $-2.07(-2.24,-1.89)^{*}$ & $-1.03(-1.23,-0.82)^{*}$ & $1.44(1.36,1.52)^{*}$ \\
\hline Aesthetic quality & $-0.63(-0.79,-0.47)^{*}$ & $-0.50(-0.66,-0.34)^{*}$ & $-0.44(-0.70,-0.19)^{*}$ & $0.82(0.72,0.93)^{*}$ \\
\hline
\end{tabular}

${ }^{*} p<0.05$.

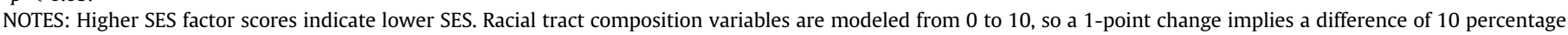
points. 
Table 4

Adjusted mean differences in Center for Epidemiologic Studies-Depression (CES-D) score associated with $10 \%$ increase in people of the same racial/ethnic group in participants' census tracts, by race/ethnicity and gender.

\begin{tabular}{|c|c|c|}
\hline Adjustment variables $^{\mathrm{a}}$ & $\begin{array}{l}\text { Mean difference } \\
\text { (s d) per } 10 \% \\
\text { increase in same } \\
\text { racial/ethnic } \\
\text { group, WOMEN }\end{array}$ & $\begin{array}{l}\text { Mean difference } \\
\text { (s d) per } 10 \% \\
\text { increase in same } \\
\text { racial/ethnic } \\
\text { group, MEN }\end{array}$ \\
\hline \multicolumn{3}{|l|}{ African Americans } \\
\hline Individual-level variables & $0.00(-0.17,0.17)$ & $0.26(0.12,0.41)^{*}$ \\
\hline Aesthetic Environment 1 mile & $-0.05(-0.22,0.12)$ & $0.23(0.08,0.37)^{*}$ \\
\hline Social cohesion 1 mile & $-0.01(-0.17,0.16)$ & $0.26(0.11,0.40)^{*}$ \\
\hline Neighborhood problems 1 mile & $-0.06(-0.24,0.12)$ & $0.24(0.09,0.38)^{*}$ \\
\hline Neighborhood Safety 1 mile & $-0.14(-0.32,0.05)$ & $0.26(0.10,0.42)^{*}$ \\
\hline SES Factor1 score & $-0.04(-0.22,0.13)$ & $0.26(0.11,0.40)^{*}$ \\
\hline SES Factor2 score & $-0.06(-0.24,0.12)$ & $0.28(0.12,0.44)^{*}$ \\
\hline ALL neighborhood variables & $-0.05(-0.27,0.16)$ & $0.31(0.13,0.48)^{*}$ \\
\hline \multicolumn{3}{|l|}{ Hispanics } \\
\hline Individual-level variables ${ }^{\mathrm{b}}$ & $-0.10(-0.36,0.17)$ & $-0.16(-0.40,0.08)$ \\
\hline Aesthetic Environment 1 mile & $-0.16(-0.43,0.11)$ & $-0.15(-0.38,0.09)$ \\
\hline Social cohesion 1 mile & $-0.15(-0.42,0.12)$ & $-0.12(-0.36,0.12)$ \\
\hline Neighborhood problems 1 mile & $-0.17(-0.44,0.10)$ & $-0.15(-0.38,0.09)$ \\
\hline Neighborhood safety 1 mile & $-0.25(-0.57,0.07)$ & $-0.25(-0.52,0.02)$ \\
\hline SES Factor 1 score & $-0.39(-0.75,-0.04)^{*}$ & $-0.31(-0.61,-0.00)^{*}$ \\
\hline SES Factor 2 score & $-0.01(-0.41,0.38)$ & $-0.33(-0.65,-0.01)^{*}$ \\
\hline ALL neighborhood variables & $-0.21(-0.65,0.24)$ & $-0.25(-0.61,0.12)$ \\
\hline \multicolumn{3}{|l|}{ Chinese } \\
\hline Individual-level variables & $-0.35(-0.76,0.06)$ & $-0.04(-0.34,0.26)$ \\
\hline Aesthetic Environment 1 mile & $-0.30(-0.69,0.08)$ & $-0.05(-0.34,0.24)$ \\
\hline Social cohesion 1 mile & $-0.33(-0.75,0.10)$ & $-0.08(-0.38,0.23)$ \\
\hline Neighborhood problems 1 mile & $-0.28(-0.67,0.11)$ & $-0.03(-0.34,0.27)$ \\
\hline Neighborhood safety 1 mile & $-0.31(-0.74,0.12)$ & $-0.01(-0.32,0.30)$ \\
\hline SES Factor 1 score & $-0.31(-0.75,0.13)$ & $0.04(-0.29,0.36)$ \\
\hline SES Factor 2 score & $-0.29(-0.71,0.12)$ & $-0.01(-0.32,0.30)$ \\
\hline ALL neighborhood variables & $-0.14(-0.56,0.28)$ & $0.03(-0.28,0.33)$ \\
\hline \multicolumn{3}{|l|}{ Whites } \\
\hline Individual-level variables & $-0.04(-0.21,0.13)$ & $-0.07(-0.22,0.08)$ \\
\hline Aesthetic Environment 1 mile & $0.01(-0.17,0.19)$ & $0.07(-0.10,0.24)$ \\
\hline Social Cohesion 1 mile & $0.01(-0.16,0.18)$ & $-0.03(-0.18,0.13)$ \\
\hline Neighborhood Problems 1 mile & $-0.01(-0.19,0.18)$ & $0.05(-0.12,0.22)$ \\
\hline Neighborhood Safety 1 mile & $0.01(-0.21,0.22)$ & $0.06(-0.13,0.25)$ \\
\hline SES Factor 1 score & $0.01(-0.20,0.22)$ & $0.11(-0.08,0.30)$ \\
\hline SES Factor 2 score & $-0.21(-0.40,-0.02)^{*}$ & $-0.16(-0.33,0.01)$ \\
\hline ALL neighborhood variables & $-0.08(-0.33,0.16)$ & $0.02(-0.20,0.23)$ \\
\hline
\end{tabular}

${ }^{*} p<0.05$.

a All models adjusted for individual-level age, and income, in addition to other (listed) neighborhood factors; Hispanic and Chinese models additionally adjusted for nativity.

b All neighborhood factors are in standard deviation units.

was generally associated with lower CES-D scores and associations often became stronger or statistically significant after adjustment for other neighborhood characteristics. This occurred because neighborhoods with greater percent Hispanic had worse neighborhood conditions (Table 3), including worse neighborhood socioeconomic status. This is consistent with prior work showing that US Hispanics live in neighborhoods with higher poverty rates than whites (Logan, 2003; Osypuk, Galea, et al., 2009), and neighborhoods with high proportions of Hispanics and Hispanic immigrants are likely to have lower income rates and be less safe (Osypuk, Roux, et al., 2009) than neighborhoods with fewer Hispanics. In contrast, associations in Chinese women were not modified after adjustment for other neighborhood characteristics, which may be due to the fact that \% Asian was not as strongly related to the other neighborhood features as \% Hispanic.

Our results for Hispanic men and women and white women (as well as for Chinese women, although confidence intervals were very wide and did not exclude the null) are consistent with the ethnic density hypothesis. It could be that neighborhood racial composition is standing in for other aspects of living environments, including household living arrangements, for which we did not control. Moreover, we did not model other aspects of the social environment that might be operating in these neighborhoods, including social capital or social control (Forrest \& Kearns, 2001). The non-significant findings amongst Chinese men and women may be due to the small sample size in this group, or could reflect weaker associations between Asian neighborhood density and social support for residents of these neighborhoods in Chicago IL and Los Angeles CA from which the Chinese sample was drawn.

We documented the most robust, statistically significant associations between neighborhood racial composition and mental health among African American men. Across all models, we found significantly detrimental associations of higher \% black neighborhoods with CES-D scores. This association was little affected by addition of other neighborhood covariates, and was strengthened considerably when all neighborhood and individual covariates were considered simultaneously. This is the only group for which we found that greater ethnic density was associated with greater depressive symptoms; these results are consistent with the residential segregation hypothesis. Almost half of our African American population lived in neighborhoods that were at least $75 \%$ African American, illustrating the importance of untangling what it is about highly segregated African American neighborhoods that are detrimental to African American men's mental health. The persistent association of neighborhood percent black with depressive symptoms may be due to other unmeasured stressors in black neighborhood environments, since neighborhood percent African American is likely to be proxying a variety of social characteristics, including high neighborhood crime, fear for the safety of one's family, discrimination, (Turner, Ross, Galster, \& Yinger, 2002) residential stability, or connection to job opportunities within the larger regional job market (Pastor, 2001). Moreover, although we controlled for several aspects of individual/household SES, there are several unmeasured aspects of SES that could account for our neighborhood effects, including wealth, unemployment, underemployment, or occupation/type of work. Lastly, measurement error in the neighborhood-level measures that we examined as possible explanatory factors is highly likely and could explain why we did not identify much of a change in estimates of the race/ethnic composition association after adjustment. We used one-mile buffers (rather than census tract based measures) to capture neighborhood characteristics around people's residences. Unfortunately race/ethnic composition data for these buffers was unavailable. It is possible that the spatial mismatch between the race/ethnic composition measures and the neighborhood measures could have contributed to the failure of the latter to fully account for associations of race/ethnic composition with depressive symptoms in some analyses.

The fact that we observed robust adverse mental health associations for neighborhood percent black among black men but not among black women suggests that there may be gendered aspects of the neighborhood environment at play that are particularly relevant for black men's mental health. Among black men residence in black neighborhoods may be proxying factors such as past trauma which are related to mental health. For example, black men are more likely to become involved in gangs and become imprisoned than black women, (Blake \& Darling, 1994) and these experiences may be correlated with neighborhood race composition and have far-reaching/long term mental health consequences (Domalanta, Risser, Roberts, \& Risser, 2003). Black men seem to engender harsher stereotyping as threatening or violent (Duncan, 1976) and greater discrimination than women in employment markets and educational contexts (Blake \& Darling, 1994) and the prevalence of these experiences may be greater in predominantly black neighborhoods. 
A small number of studies have examined the association between neighborhood racial/ethnic concentration and depression/depressive symptoms in the United States (Mair, Roux, \& Galea, 2008). Similar to our findings for Hispanics, a study of elderly Mexican Americans found that increased ethnic density had a protective effect on depressive symptoms amongst US Hispanics (Ostir, Eschbach, Markides, \& Goodwin, 2003). The literature has drawn inconsistent conclusions for African American populations. Community ethnic identification lowered levels of clinical depression amongst elderly African Americans living in Baltimore, (Simons et al., 2002) and living in an area with high racial congruence (high \% of people of the same racial/ethnic background in participants' neighborhoods) was associated with lower levels of depressive symptoms and clinical depression for both black men and women living in Baltimore (Tweed et al., 1990). Other studies however have found no clear association of \% black with depressive symptoms after adjustment for individual-level confounders (Henderson et al., 2005; Kubzansky et al., 2005). It is clear that the association between \% African American and depressive symptoms amongst African Americans needs to be further explored, as results have been conflicting.

Several studies have examined associations in other developed countries. A study of adolescents in Canada found no association between minority racial/ethnic concentration and depression, (Abada, Hou, \& Ram, 2007) while a study in the UK found that increased minority concentration was associated with lower levels of depression and anxiety amongst minority groups (Halpern \& Nazroo, 2000). Many prior studies did not examine the effect of racial/ethnic neighborhood concentration separately for individual racial/ethnic groups, (Aneshensel et al., 2007; la Gory \& Fitpatrick, 1992; Kubzansky et al., 2005; Xue, Leventhal, Brooks-Gunn, \& Earls, 2005) making it difficult to compare these to our results.

While we had a large overall sample size, when broken down by race/ethnicity and gender some of our groups had sample sizes under 350, which may have been inadequate to accurately examine the associations of interest. For example, associations in Chinese women were quite strong although they never reached statistical significance. The distribution of race/ethnic composition differed substantially across race/ethnic groups, making comparisons of associations difficult. There was an indication that the associations may be non-linear in some groups, but the small sample size made it difficult for us to fully explore the shape of the associations. Possible non-linearity across the range of race/ethnic composition levels observed needs further exploration in datasets with larger sample sizes. MESA included participants in six different study sites. It is plausible that the meaning and implications for health of neighborhood race/ethnic composition varies across sites. For example, a neighborhood with a majority of Hispanic residents in New York City may have very different social interactions than one in Minneapolis. The white residents were sampled from six unique geographic locations, while the Chinese came from only two. Unfortunately limited sample size made it difficult to examine heterogeneity by site, although no interaction terms were statistically significant. Finally, for practical reasons related to data availability we used census tracts as crude proxies for the relevant race/ ethnic composition context, which undoubtedly introduced important measurement error.

A major challenge in estimating effects of neighborhood context on health is accounting for the selection of persons into neighborhoods based on other characteristics related to the outcome. We evaluated the robustness of our results to extrapolations using propensity score matching and found qualitatively similar results. Selection effects may be especially important for recent immigrants, who may choose to live in neighborhoods based on prior social networks as part of their immigrant assimilation process
(Iceland \& Scopilliti, 2008; Portes \& Bach, 1985; Portes \& Rumbaut, 2006). To the extent that prior mental health status is related to neighborhood selection, this process could have biased our results. In contrast, the degree of residential choice may be more limited for native-born blacks, Hispanics and other minority groups as compared with whites or immigrants due to a variety of factors, including discrimination and racism in housing markets (Iceland \& Scopilliti, 2008)

The experience of living in a highly segregated neighborhood in the United States may be different than in other countries. In Canada, for example, highly segregated areas are not necessarily low-income ones (Abada et al., 2007). In the United States, however, racially segregated areas (especially predominantly African American areas) tend to be associated with higher crime and poverty (Massey, 1995: pp. 1203-1232; Morenoff, 2003; Williams \& Collins, 2001). Our finding that African American men have higher levels of depressive symptoms in neighborhoods with greater concentrations of African Americans may be specific to the United States. We have identified no studies outside the US that found higher minority racial/ethnic concentration to be associated with higher levels of depression/depressive symptoms. On the other hand, there is some evidence that the social support effect posited by the ethnic density hypothesis is operating in countries outside the US (Becares et al., 2009). An added complication is that both the ethnic density and residential segregation effects could operate simultaneously in some groups. Because their effects are opposite, they could conceivably cancel each other out. This is impossible to determine from the observational data we have.

In summary, we documented associations of neighborhood race/ethnic composition with depressive symptoms in African American men and to some extent in Hispanics and in Chinese women in a large US sample. The neighborhood variables we measured did not appear to explain observed patterns. Future work needs to replicate these kinds of analyses in other large multiethnic samples as well as to more fully examine the processes generating these associations. Additional cross-country comparisons of the associations of residential segregation with mental health may also shed light on the processes involved. Identifying whether and why neighborhood composition is associated with mental health may provide important clues regarding the social and psychological processes that cause or facilitate the development of depression and may suggest new avenues for prevention, especially in minority groups.

\section{Acknowledgements}

This work was supported in part by the Center for Integrative Approaches to Health Disparities P60 MD002249 (Diez Roux). MESA was supported by contracts N01-HC-95159 through N01-HC95169 from the National Heart, Lung, and Blood Institute. The authors thank the other investigators, the staff, and the participants of the MESA study for their valuable contributions. A full list of participating MESA investigators and institutions can be found at http://www.mesa-nhlbi.org.

\section{References}

Abada, T., Hou, F., \& Ram, B. (2007). Racially mixed neighborhoods, perceived neighborhood social cohesion, and adolescent health in Canada. Social Science $\mathcal{E}$ Medicine, 65(10), 2004-2017.

Acevedo-Garcia, D. \& Osypuk, T. L. (2008). Impacts of housing and neighborhoods on health: pathways, racial/ethnic disparities, and policy directions. In J. H. Carr, \& N. K. Kutty (Eds.), Segregation: The rising costs for America (pp. 197-235). New York: Routledge.

Acevedo-Garcia, D., Osypuk, T. L., McArdle, N., \& Williams, D. R. (2008). Toward a policy-relevant analysis of geographic and racial/ethnic disparities in child health. Health Affairs (Millwood), 27(2), 321-333. 
Aneshensel, C. S., \& Sucoff, C. A. (1996). The neighborhood context of adolescent mental health. Journal of Health and Social Behavior, 37(4), 293-310.

Aneshensel, C. S., Wight, R. G., Miller-Martinez, D., Botticello, A. L., Karlamangla, A. S., \& Seeman, T. E. (2007). Urban neighborhoods and depressive symptoms among older adults. The Journals of Gerontology. Series B, Psychological Sciences and Social Sciences, 62(1), S52-S59.

Ball, K., Bauman, A., Leslie, E., \& Owen, N. (2001). Perceived environmental aesthetics and convenience and company are associated with walking for exercise among Australian adults. Preventive Medicine, 33(5), 434-440.

Becares, L., Nazroo, J., \& Stafford, M. (2009). The buffering effects of ethnic density on experienced racism and health. Health \& Place, 15(3), 670-678.

Berke, E. M., Gottlieb, L. M., Moudon, A. V., \& Larson, E. B. (2007). Protective association between neighborhood walkability and depression in older men. Journal of the American Geriatrics Society, 55(4), 526-533.

Bild, D. E., Bluemke, D. A., Burke, G. L., Detrano, R., Diez Roux, A. V., Folsom, A. R., et al. (2002). Multi-ethnic study of atherosclerosis: objectives and design. American Journal of Epidemiology, 156(9), 871-881.

Blake, W. M., \& Darling, C. A. (1994). The dilemmas of the African American male. Journal of Black Studies, 24(4), 402-415.

Diez Roux, A. V., Detrano, R., Jackson, S., Jacobs, D. R., Jr., Schreiner, P. J., Shea, S., et al. (2005). Acculturation and socioeconomic position as predictors of coronary calcification in a multiethnic sample. Circulation, 112(11), 1557-1565.

Domalanta, D. D., Risser, W. L., Roberts, R. E., \& Risser, J. M. (2003). Prevalence of depression and other psychiatric disorders among incarcerated youths. Journal of the American Academy of Child and Adolescent Psychiatry, 42(4), 477-484

Duncan, B. L. (1976). Differential social perception and attribution of intergroup violence: testing the lower limits of sterotyping of blacks. Journal of Personality and Social Psychology, 34(4), 590-598.

Echeverria, S., Diez Roux, A. V., Shea, S., Borrell, L. N., \& Jackson, S. (2008). Associations of neighborhood problems and neighborhood social cohesion with mental health and health behaviors: the multi-ethnic study of atherosclerosis. Health E Place, 14(4), 851-863.

Eschbach, K., Ostir, G. V., Patel, K. V., Markides, K. S., \& Goodwin, J. S. (2004). Neighborhood context and mortality among older Mexican Americans: is there a barrio advantage? American Journal of Public Health, 94(10), 1807-1812.

Fernandez Kelly, M. P., \& Schauffler, R. (1996). Divided fates: immigrant children and the new assimilation. In A. Portes (Ed.), The new second generation (pp. 30-53). New York: Russell Sage Foundation.

Fitzpatrick, K. M., Piko, B. F., Wright, D. R., \& LaGory, M. (2005). Depressive symptomatology, exposure to violence, and the role of social capital among African American adolescents. American Journal Orthopsychiatry, 75(2), 262-274.

Forrest, R., \& Kearns, A. (2001). Social cohesion, social capital and the neighborhood. Urban Studies, 38(12), 2125-2143.

Gary, T. L., Stark, S. A., \& LaVeist, T. A. (2007). Neighborhood characteristics and mental health among African Americans and whites living in a racially integrated urban community. Health \& Place, 13(2), 569-575.

la Gory, M., \& Fitpatrick, K. (1992). The effects of environmental context on elderly depression. Journal of Aging and Health, 4(4), 459-479.

Gutman, L. M., \& Sameroff, A. J. (2004). Continuities in depression from adolescence to young adulthood: contrasting ecological influences. Journal of Personality and Social Psychology, 16(4), 967-984.

Hadley-Ives, E., Stiffman, A. R., Elze, D., Johnson, S. D., \& Dore, P. (2000). Measuring neighborhood and school environments: perceptual and aggregate approaches. Journal of Human Behavior in the Social Environment, 3(1), 1-28.

Halpern, D. (1993). Minorities and mental health. Social Science E Medicine, 36(5) 597-607.

Halpern, D., \& Nazroo, J. (2000). The ethnic density effect: results from a national community survey of England and Wales. The International Journal of Social Psychiatry, 46(1), 34-46.

Henderson, C., Diez Roux, A. V., Jacobs, D. R., Jr., Kiefe, C. I., West, D., \& Williams, D. R. (2005). Neighbourhood characteristics, individual level socioeconomic factors, and depressive symptoms in young adults: the CARDIA study. Journal of Epidemiology and Community Health, 59(4), 322-328.

Hernan, M. A., Hernandez-Diaz, S., \& Robins, J. M. (2004). A structural approach to selection bias. Epidemiology, 15(5), 615-625.

Iceland, J., \& Scopilliti, M. (2008). Immigrant residential segregation in U.S metropolitan areas, 1990-2000. Demography, 45(1), 79-94.

Joffe, M. M., \& Rosenbaum, P. R. (1999). Invited commentary: propensity scores. American Journal of Epidemiology, 150(4), 327-333.

Kubzansky, L. D., Subramanian, S. V., Kawachi, I., Fay, M. E., Soobader, M. J., \& Berkman, L. F. (2005). Neighborhood contextual influences on depressive symptoms in the elderly. American Journal of Epidemiology, 162(3), 253-260.

Littell, R. C., Milliken, G. A., Stroup, W. W., \& Wolfinger, R. D. (1996). SAS system for mixed models. Cary, NC: SAS Institute Inc.

Logan, J. R. (2003). America's newcomers. Albany NY: Lewis Mumford Center for Comparitive Urban and Regional Research. http://mumford.albany.edu/census/ NewComersReport/NewComer01.htm.
Mair, C., Diez Roux, A. V., Shen, M., Shea, S., Seeman, T., Echeverria, S., et al. (2009) Cross-sectional and longitudinal associations of neighborhood cohesion and stressors with depressive symptoms in the multiethnic study of atherosclerosis. Annals of Epidemiology, 19(1), 49-57.

Mair, C., Diez Roux, A. V., \& Galea, S. (2008). Are neighbourhood characteristics associated with depressive symptoms? A review of evidence. Journal of Epidemiology $\mathcal{E}$ ' Community Health, 62(11), 940-946.

Massey, D. S. (1995)Getting away with murder: Segregation and violent crime in urban America, Vol. 143. University of Pennsylvania Law Review.

Massey, D. (2001). Residential segregation and neighborhood conditions in U.S metropolitan areas. In N. J. Smelser, W. J. Wilson, \& F. Mitchell (Eds.), America becoming: Racial trends and their consequences (pp. 391-434). National Academy Press.

Morenoff, J. D. (2003). Neighborhood mechanisms and the spatial dynamics of birth weight. American Journal of Sociology, 108(5), 976-1017.

Mujahid, M. S., Diez Roux, A. V., Morenoff, J. D., \& Raghunathan, T. (2007). Assessing the measurement properties of neighborhood scales: from psychometrics to ecometrics. American Journal of Epidemiology, 165(8), 858-867.

Mujahid, M. S., Diez Roux, A. V., Morenoff, J. D., Raghunathan, T. E., Cooper, R. S $\mathrm{Ni}, \mathrm{H}$., et al. (2008). Neighborhood characteristics and hypertension. Epidemiology, 19(4), 590-598

Ostir, G. V., Eschbach, K., Markides, K. S., \& Goodwin, J. S. (2003). Neighbourhood composition and depressive symptoms among older Mexican Americans. Journal of Epidemiology \& Community Health, 57(12), 987-992.

Osypuk, T. L., Galea, S., McArdle, N., \& Acevedo-Garcia, D. (2009). Quantifying separate and unequal: racial/ethnic distributions of neighborhood poverty in metropolitan America. Urban Affairs Review, 45(1), 25-65.

Osypuk, T. L., Diez Roux, A. V., Hadley, C., \& Kandula, N. R. (2009). Are immigrant enclaves healthy places to live? The multi-ethnic study of atherosclerosis. Social Science $\mathcal{E}$ Medicine, 69(1), 110-120.

Pastor, M. (2001). Geography and opportunity. In N. J. Smelser, W. J. Wilson, \& F. Mitchell (Eds.), America becoming: Racial trends and their consequences, Vol. (pp. 435-468). Washington DC: National Academy Press.

Pickett, K. E., \& Wilkinson, R. G. (2008). People like us: ethnic group density effects on health. Ethnicity \& Health, 13(4), 321-334.

Portes, A., \& Bach, R. L. (1985). Latin journey: Cuban and Mexican immigrants in the United States. Berkeley, CA: University of California Press.

Portes, A., \& Rumbaut, R. G. (2006). Immigrant America: A portrait. Berkeley, CA: University of California Press.

Radloff, L. (1977). The CES-D scale: a self-report depression scale for research in the general population. Applied Psychological Measurement, 1, 385-401.

Rosenbaum, P. R., \& Rubin, D. B. (1985). Constructing a control group using multivariate matched sampling methods that incorporate the propensity score. The American Statistician, 39, 33-38.

Sampson, R. J., Raudenbush, S. W., \& Earls, F. (1997). Neighborhoods and violent crime: a multilevel study of collective efficacy. Science, 277(5328), 918-924.

Simons, R. L., Murry, V., McLoyd, V., Lin, K. H., Cutrona, C., \& Conger, R. D. (2002). Discrimination, crime, ethnic identity, and parenting as correlates of depressive symptoms among African American children: a multilevel analysis. Development and Psychopathology, 14(2), 371-393.

Turner, M. A., Ross, S. L., Galster, G. C., \& Yinger, J. (2002). Discrimination in metropolitan housing markets: Phase I. Washington DC: US Dept of HUD.

Tweed, D. L., Goldsmith, H. F., Jackson, D. J., Stiles, D., Rae, D. S., \& Kramer, M. (1990). Racial congruity as a contextual correlate of mental disorder. The American Journal of Orthopsychiatry, 60(3), 392-403.

Velez-Ibanez, C. (1993). U.S. Mexicans in the Borderlands: being poor without the underclass. In J. Moore, \& R. Pinderhughes (Eds.), The Barrios: Latinos and the underclass debate (pp. 195-220). New York: Russell Sage Foundation.

Veling, W., Susser, E., van Os, J., Mackenbach, J. P., Selten, J. P., \& Hoek, H. W. (2008). Ethnic density of neighborhoods and incidence of psychotic disorders among immigrants. American Journal of Psychiatry, 165(1), 66-73.

Weich, S., Lewis, G., \& Jenkins, S. P. (2001). Income inequality and the prevalence of common mental disorders in Britain. British Journal of Psychiatry, 178 222-227.

Weich, S., Twigg, L., Holt, G., Lewis, G., \& Jones, K. (2003). Contextual risk factors for the common mental disorders in Britain: a multilevel investigation of the effects of place. Journal of Epidemiology \& Community Health, 57(8), 616-621.

Whitley, R., Prince, M., McKenzie, K., \& Stewart, R. (2006). Exploring the ethnic density effect: a qualitative study of a London electoral ward. The Internationa Journal of Social Psychiatry, 52(4), 376-391.

Williams, D. R., \& Collins, C. (2001). Racial residential segregation: a fundamental cause of racial disparities in health. Public Health Reports, 116(5), 404-416.

Xue, Y., Leventhal, T., Brooks-Gunn, J., \& Earls, F. J. (2005). Neighborhood residence and mental health problems of 5- to 11-year-olds. Archives of General Psychiatry, 62(5), 554-563. 